\title{
ANÁLISE DO NÍVEL COGNITIVO DO EXAME DE SUFICIÊNCIA CONTÁBIL NA PERSPECTIVA DA TAXONOMIA DE BLOOM
}

\author{
Daniella Andrade Arantes 1
}

Denise Mendes da Silva ${ }^{2}$

- Artigo recebido em: 20/03/2019 -• Artigo aceito em: 06/02/2020 --' Segunda versão aceita em: 06/04/2020

\section{RESUMO}

A pesquisa tem como objetivo confrontar o nível cognitivo do Exame de Suficiência com as habilidades e competências requeridas do contador a partir dos objetivos educacionais da Taxonomia de Bloom. Para tanto, realizou-se a classificação de 569 questões de Contabilidade retiradas de 14 edições do Exame de Suficiência (2011.1 a 2017.2) de acordo com os seis níveis cognitivos da taxonomia. Adicionalmente foi realizado um processo de validação da classificação das questões que geraram dúvidas quanto ao nível cognitivo a que pertencem, composto de quatro etapas, mediante a colaboração de quatro especialistas, conhecedoras da Taxonomia de Bloom. Os dados foram submetidos à análise descritiva. Os resultados apontam que o Exame de Suficiência não está alinhado ao perfil esperado do contador e que o CFC (Conselho Federal de Contabilidade) precisa evoluir no sentido de avaliar se os bacharéis em Contabilidade no Brasil são capazes de acompanhar as práticas contábeis globais, ou seja, se os futuros profissionais contábeis possuem as habilidades e competências requeridas do contador no cenário nacional e internacional.

Palavras-Chave: Exame de Suficiência Contábil, Avaliação, Taxonomia de Bloom, Competências.

\footnotetext{
1 Mestre em Contabilidade Financeira pela FACIC/UFU. Endereço: Av. João Naves de Ávila, 2121, Santa Mônica, CEP: 38.400-902, Uberlândia-MG, Brasil. E-mail: dani.cont92@hotmail.com https://orcid.org/0000-0003-2026-5818.

2 Doutora em Controladoria e Contabilidade pela FEA-RP/USP. Professora Adjunta da Faculdade de Ciências Contábeis da Universidade Federal de Uberlândia (FACIC/UFU). Endereço: Av. João Naves de Ávila, 2121, Santa Mônica, CEP: 38.400-902, Uberlândia-MG, Brasil. E-mail: denise.mendes@ufu.br https://orcid.org/0000-0002-1490-5148.
}

Editora responsável pela aprovação do artigo: $\mathrm{Dr}^{\mathrm{a}}$. Bruna Camargos Avelino Editora responsável pela edição do artigo: $\mathrm{Dr}^{\mathrm{a}}$. Bruna Camargos Avelino 


\title{
ANALYSIS OF THE COGNITIVE LEVEL OF THE ACCOUNTING SUFFICIENCY EXAM FROM THE BLOOM'S TAXONOMY PERSPECTIVE
}

\begin{abstract}
The research aims to compare the cognitive level of the Sufficiency Exam with the skills and competencies required of the accountant based on the educational objectives of Bloom's Taxonomy. To do so, 569 Accounting questions from 14 editions of the Sufficiency Exam (2011.1 to 2017.2) was classified according to the six cognitive levels of the taxonomy. In addition, a validation of the classification of the questions was carried out, composed of four stages, through the collaboration of four experts, who are familiar with the Bloom's Taxonomy. Data were submitted to descriptive analysis. The results indicate that the Sufficiency Exam is not aligned with the expected profile of the accountant and that the CFC must evolve in order to evaluate whether the Brazilian Accounting Bachelors are able to follow global accounting practices, if future accounting professionals have the required skills and competencies of the accountant in the national and international scenario.
\end{abstract}

Keywords: Accounting Sufficiency Exam, Evaluation, Bloom's Taxonomy, Skills.

\section{INTRODUÇÃO}

No Brasil, os egressos e estudantes do último ano do curso de Ciências Contábeis estão aptos a realizar o Exame de Suficiência desenvolvido pelo Conselho Federal de Contabilidade (CFC), com objetivo de obter certificação profissional. Estabelecido pelo art. 12 do Decreto-Lei n. 9.295/46, o exame é aplicado duas vezes por ano e é composto por cinquenta questões de múltipla escolha, das quais, vinte e cinco questões precisam ser respondidas corretamente pelo candidato para que o mesmo obtenha aprovação.

Por ter caráter classificatório, ser realizado ao final de um período de aprendizagem e ter como foco a nota, o Exame de Suficiência pode ser enquadrado no que se chama função somativa da avaliação (Haydt, 1991; Silva, Theiss \& Rausch, 2013). Além disso, pode ser denominado como teste objetivo, pois as questões têm uma resposta correta e são mais fáceis para os avaliadores pontuarem (Shaftel \& Shaftel, 2007).

De acordo com Haydt (1991), as competências de aprendizagem medidas por um teste devem refletir fielmente os objetivos educacionais propostos. Para tal, existem guias que ajudam na formulação de objetivos educacionais e na construção de instrumentos de avaliação válidos e fidedignos. O mais conhecido e utilizado é o domínio cognitivo da Taxonomia de objetivos educacionais de Bloom (Pelissoni, 2009; Silva, 2014).

No contexto da Contabilidade encontram-se estudos que analisaram o nível cognitivo exigido em provas do Exame de Suficiência (Pinheiro, Dias, Lima \& Lopes, 2013; Silva, 2014; Martinez, 2017; Bernardes \& Silva, 2019) utilizando essa taxonomia. No entanto, nesses estudos não houve uma avaliação completa de todas as edições do exame, notadamente no período após a convergência às 
normas internacionais de contabilidade (IFRS - International Financial Reporting Standards), ocorrida no Brasil de forma plena no ano de 2010.

A convergência às IFRS se deu em mais de 140 países, incluindo o Brasil, e, em decorrência desse processo, o mercado passou a demandar dos contadores, além das competências teóricas e técnicas (hard skills), competências comportamentais, conhecidas na literatura como soft skills (Kavanagh \& Drennan, 2008). Esse aspecto pode refletir no âmbito educacional e, consequentemente, nos sistemas de avaliação, pois novas competências, como julgamento na aplicação de critérios contábeis e pensamento crítico, por exemplo, precisam ser abordadas. Em outras palavras, passa-se a buscar uma formação integral para o contador, de modo a proporcionar o desenvolvimento das hard e das soft skills (Gomes, 2018).

Além da questão da abrangência das edições do Exame de Suficiência, os estudos anteriores mencionados não realizaram uma validação da classificação das questões em níveis cognitivos, o que pode ser uma limitação para os resultados encontrados, visto a subjetividade do processo de classificação. Acredita-se que a subjetividade é inerente ao processo de classificação, porém a mesma pode ser minimizada a partir de visões adicionais a do pesquisador. Dessa forma, metodologicamente, esse estudo diferencia-se dos demais, pois apresenta um processo de validação da classificação das questões que geraram dúvida quanto ao nível cognitivo a que pertencem, composto de quatro etapas, mediante a colaboração de quatro especialistas, conhecedoras da Taxonomia de Bloom. Nessa conjuntura, o objetivo deste estudo é confrontar o nível cognitivo do Exame de Suficiência com as habilidades e competências requeridas do contador a partir dos objetivos educacionais da Taxonomia de Bloom. Para isso, foram classificadas, conforme essa taxonomia, as questões de contabilidade das provas do Exame de Suficiência do CFC desde a primeira edição de 2011 até a segunda de 2017, última disponível na época de realização da pesquisa (abril de 2018).

Almeja-se que esse estudo contribua no sentido de agregar informações úteis ao CFC, para que possa alinhar o que é cobrado no Exame de Suficiência com o currículo do curso de Ciências Contábeis das Instituições de Ensino Superior e com o perfil desejado pelo mercado para os contadores (habilidades e competências). Conforme Gomes (2018), para a sociedade é positiva a presença de indivíduos com visão relacional global, capazes de se comunicar, pensar criticamente, colaborar e solucionar problemas.

Espera-se, ainda, que este estudo possa motivar as Instituições de Ensino Superior a acompanhar as mudanças no perfil profissional desejado e priorizar o desenvolvimento da capacidade cognitiva dos futuros contadores, bem como estabelecer objetivos educacionais claros e específicos, de modo que seja possível observar sua evolução. Ademais, acredita-se que a disponibilização da pesquisa aos envolvidos com o ensino da Contabilidade, permitirá conhecer como é construído o Exame de Suficiência e se o CFC considera, na sua elaboração, as competências que os bacharéis em Ciências Contábeis necessitam desenvolver ou aperfeiçoar para atuar profissionalmente segundo as práticas globais de Contabilidade. 


\section{REVISÃO DA LITERATURA}

\subsection{Taxonomia de Bloom}

A taxonomia completa proposta por Bloom com finalidade de classificar os objetivos educacionais é constituída de três partes principais denominadas: domínio afetivo, domínio psicomotor e domínio cognitivo. Este estudo limitou-se à análise do domínio cognitivo, porque, além de ser o mais conhecido e utilizado, é o que apresenta as mais claras definições de objetivos expressas em termos de comportamento do estudante, sendo, dessa forma, fundamental para a implementação da avaliação escolar (Bloom, Engelhart, Furst, Hill \& Krathwohl, 1983; Silva, 2014).

Conforme Bloom et al. (1983) no domínio cognitivo estão os objetivos relacionados à memória ou recognição, ou seja, examinar algo para reconhecêlo, e ao desenvolvimento de habilidades intelectuais. Estes autores sugerem uma estrutura da taxonomia do domínio cognitivo constituída por seis níveis principais, ordenados da seguinte forma: 1) conhecimento, 2) compreensão, 3) aplicação, 4) análise, 5) síntese e 6) avaliação, como demonstrado na Figura 1. Os autores enfatizam que essa é uma estrutura sugerida, hierarquizada, partindo dos comportamentos educacionais mais simples para os mais complexos, ou seja, o indivíduo só avança de nível depois de dominar o anterior, isto é, as classes são dependentes.

\begin{tabular}{|c|c|}
\hline Nível cognitivo & Descrição \\
\hline 1. Conhecimento & $\begin{array}{l}\text { Habilidade de lembrar informações e conteúdos previamente } \\
\text { abordados como fatos, datas, palavras, teorias, métodos, } \\
\text { classificações, lugares, regras, critérios, procedimentos etc. A } \\
\text { habilidade pode envolver lembrar uma significativa quantidade de } \\
\text { informações ou fatos específicos. O objetivo principal deste nível é } \\
\text { trazer à consciência esses conhecimentos. } \\
\text { Verbos: enumerar, definir, descrever, identificar, listar, nomear, } \\
\text { combinar, apontar, relembrar, relacionar, reproduzir, solucionar, } \\
\text { declarar, rotular, memorizar e reconhecer. } \\
\text { Uma definição de depreciação seria um exemplo para o nível 1. }\end{array}$ \\
\hline 2. Compreensão & $\begin{array}{l}\text { Habilidade de compreender e dar significado ao conteúdo. Essa } \\
\text { habilidade pode ser demonstrada por meio da tradução do } \\
\text { conteúdo compreendido para uma nova forma (oral, escrita, } \\
\text { diagramas etc.) ou contexto. Nessa categoria, encontra-se a } \\
\text { capacidade de entender a informação ou fato, de captar seu } \\
\text { significado e de utilizá-la em contextos diferentes. } \\
\text { Verbos: alterar, construir, definir, distinguir, estimar, explicar, } \\
\text { generalizar, inferir, prever, reescrever, resolver, discutir, identificar, } \\
\text { interpretar, situar e traduzir. } \\
\text { Explicar por que a depreciação é necessária seria nível } 2 .\end{array}$ \\
\hline 3. Aplicação & $\begin{array}{l}\text { Habilidade de usar informações, métodos e conteúdos aprendidos } \\
\text { em novas situações concretas. Isso pode incluir aplicações de regras, } \\
\text { métodos, modelos, conceitos, princípios, leis e teorias. } \\
\text { Verbos: aplicar, alterar, demonstrar, desenvolver, descobrir, ilustrar, } \\
\text { modificar, organizar, prever, resolver, usar, construir, esboçar, escrever, } \\
\text { operar e praticar. } \\
\text { Computar a despesa de depreciação seria um exemplo nesse nível. }\end{array}$ \\
\hline
\end{tabular}




\begin{tabular}{|c|c|}
\hline Nível cognitivo & Descrição \\
\hline 4. Análise & $\begin{array}{l}\text { Habilidade de subdividir o conteúdo em partes menores com a } \\
\text { finalidade de entender a estrutura final. Essa habilidade pode incluir a } \\
\text { identificação das partes, análise de relacionamento entre as partes e } \\
\text { reconhecimento dos princípios organizacionais envolvidos. Identificar } \\
\text { partes e suas inter-relações. Nesse ponto é necessário não apenas ter } \\
\text { compreendido o conteúdo, mas também a estrutura do objeto de } \\
\text { estudo. } \\
\text { Verbos: analisar, reduzir, determinar, deduzir, diferenciar, identificar, } \\
\text { apontar, inferir, relacionar, selecionar, subdividir, examinar, testar, } \\
\text { esquematizar e questionar. } \\
\text { Preparar uma entrada de diário para depreciação seria um exemplo. }\end{array}$ \\
\hline 5. Síntese & $\begin{array}{l}\text { Habilidade de agregar e juntar partes com a finalidade de criar um } \\
\text { novo todo. Essa habilidade envolve a produção de uma } \\
\text { comunicação única (tema ou discurso), um plano de operações } \\
\text { (propostas de pesquisas) ou um conjunto de relações abstratas } \\
\text { (esquema para classificar informações). Combinar partes não } \\
\text { organizadas para formar um "todo". } \\
\text { Verbos: combinar, compor, construir, criar, explicar, formular, } \\
\text { organizar, propor, relacionar, revisar, resumir, sistematizar, escrever, } \\
\text { desenvolver, estruturar e projetar. } \\
\text { A alteração do método usado para registrar a depreciação seria um } \\
\text { exemplo de síntese. }\end{array}$ \\
\hline 6. Avaliação & $\begin{array}{l}\text { Habilidade de julgar o valor do material (proposta, pesquisa, projeto) } \\
\text { para um propósito específico. O julgamento é baseado em critérios } \\
\text { bem definidos que podem ser externos (relevância) ou internos } \\
\text { (organização) e podem ser fornecidos ou conjuntamente } \\
\text { identificados. Julgar o valor do conhecimento. } \\
\text { Verbos: Avaliar, comparar, concluir, criticar, decidir, explicar, } \\
\text { interpretar, justificar, relatar, resolver, resumir, escrever um review } \\
\text { sobre, detectar, julgar e selecionar. } \\
\text { Um exemplo de avaliação seria comparar diferentes métodos de } \\
\text { cálculo de depreciação e argumentar qual método é preferível para } \\
\text { uma situação específica. }\end{array}$ \\
\hline
\end{tabular}

Figura 1 - Níveis cognitivos da Taxonomia de Bloom

Fonte: Adaptado de Pinheiro et al. (2013) e Davidson e Baldwin (2005).

Para Bloom et al. (1983) no primeiro nível da taxonomia, os objetivos educacionais dão mais ênfase aos processos psicológicos da memória, ou seja, a evocação é o principal processo psicológico nele envolvido. O segundo representa o nível mais baixo do entendimento, pois o indivíduo entende a ideia literal comunicada de forma oral ou escrita, verbal ou simbólica, pode fazer uso dela, porém não a relaciona com outras ou não percebe as suas verdadeiras implicações. Sobre o terceiro nível é relevante realçar que, para que algo seja aplicado, deve primeiro ser compreendido, o que demonstra claramente a dependência desse nível com o anterior. As habilidades envolvidas no quarto nível da taxonomia são consideradas mais complexas que as dos níveis anteriores e tratam do conteúdo e da forma do material de uma comunicação. O penúltimo nível possibilita que o aluno tenha mais autonomia, no sentido de construir seu próprio conhecimento, pois ele vai criar ou formar um todo bem estruturado a partir da combinação de partes. Finalmente, o último nível da taxonomia possibilita julgar o valor das ideias, podendo-se dizer que engloba todas as classes de comportamento anteriormente descritas. 
Diferentes técnicas e instrumentos podem ser usados para avaliar e devem ser escolhidos de acordo com os objetivos que se deseja atingir e os conteúdos abordados. Como exemplos de recursos de avaliação citam-se a testagem (testes), as questões dissertativas, a inquirição (entrevista e questionário), a observação, os portfólios e as pesquisas (Haydt, 1991; Shaftel \& Shaftel, 2007). Salienta-se que, nessa pesquisa, serão enfatizados os testes, devido ao objeto de estudo escolhido (Exame de Suficiência) se enquadrar nessa categoria de instrumentos de avaliação e, também, por serem os mais comumente utilizados.

Diante do exposto, é importante destacar que é fundamental que os instrumentos de avaliação reúnam os diferentes níveis da taxonomia, uma vez que o equilíbrio entre eles, de acordo com Pelissoni (2009, p. 136), possibilita que "a relação de ensino e aprendizagem desenvolva nos alunos diferentes competências visando a sua atuação profissional em contexto multifacetado e multideterminado, que exige do indivíduo diferentes habilidades para a resolução de uma rede de situações complexas".

\subsection{Habilidades e Competências}

A convergência das normas brasileiras, fortemente vinculadas ao fisco, às IFRS impactou a cultura contábil no país, no qual as regras, típicas de regimes code law, que estabeleciam o modus operandi da prática contábil no país, foram suplantadas por conceitos com maior grau de subjetividade, baseados em princípios, com os quais os profissionais brasileiros, assim como os professores e instituições de ensino, não estavam habituados e nem preparados para lidar (Gomes, 2018).

Diante desse contexto o ensino da contabilidade muda substancialmente, pois o mercado de trabalho passa a exigir dos profissionais da área um conhecimento que ultrapassa a questão técnica e teórica (Lemes \& Miranda, 2014). Assim, espera-se que os objetivos educacionais no Brasil estejam voltados, também, para o desenvolvimento e aprimoramento de competências comportamentais, que tenham como fim produzir um novo perfil acadêmico a professores e estudantes de contabilidade (Gomes, 2018). Nessa perspectiva, percebe-se a necessidade de que as instituições de ensino, professores e reguladores da educação contábil se preocupem com a formação dos contadores e saibam da existência de órgãos internacionais que apoiam o ensino das IFRS mediante uma abordagem efetiva, por exemplo, o IAESB (International Accounting Education Standards Board).

O IAESB é um órgão autônomo, apoiado e financiado pela IFAC (International Federation of Accountants), que formula padrões internacionais de educação contábil de alta qualidade, denominados IES (International Education Standards). Os IES são publicados no Handbook of International Education Pronouncements, servem como referência internacional de boas práticas e o seu desenvolvimento, adoção e implementação tem como objetivo servir o interesse público, por meio do fortalecimento mundial da profissão contábil e do aprimoramento da competência profissional. Logo, os materiais sobre IFRS desenvolvidos por esses órgãos podem ajudar as instituições de ensino, professores e reguladores a educar os alunos de maneira mais eficaz e alinhar os seus currículos e exames com as necessidades profissionais advindas do processo de convergência. 
De acordo com o Handbook of International Education Pronouncements (IFAC, 2019), o objetivo geral da educação profissional em Contabilidade é desenvolver e manter a competência profissional dos contadores aspirantes e atuantes. Dentro dos IES a competência profissional é a integração e a aplicação de (a) competência técnica (IES 2), (b) habilidades profissionais (IES 3) e (c) valores profissionais, ética e atitudes (IES 4), conforme demonstrado na Figura 2.

\begin{tabular}{|c|c|}
\hline $\begin{array}{l}\text { Conhecimentos de } \\
\text { Competência técnica } \\
\text { (IES 2) }\end{array}$ & $\begin{array}{l}\text { (a) Contabilidade financeira e relatórios (Intermediário); } \\
\text { (b) Contabilidade de gestão (Intermediário); } \\
\text { (c) Finanças e gestão financeira (Intermediário); } \\
\text { (d) Tributação (Intermediário); } \\
\text { (e) Auditoria e garantia (Intermediário); } \\
\text { (f) Governança, gerenciamento de riscos e controle interno } \\
\text { (Intermediário); } \\
\text { (g) Leis e regulamentos de negócios (Intermediário); } \\
\text { (h) Tecnologia da informação (Intermediário); } \\
\text { (i) Ambiente empresarial e organizacional (Intermediário); } \\
\text { (j) Economia (Fundamental); } \\
\text { (k) Estratégia e gestão empresarial (Intermediário) }\end{array}$ \\
\hline $\begin{array}{l}\text { Habilidades } \\
\text { profissionais (IES 3) }\end{array}$ & $\begin{array}{l}\text { (a) Intelectual, se relaciona com a capacidade de um contador } \\
\text { profissional para resolver problemas, tomar decisões e exercer } \\
\text { juízo profissional (Intermediário); } \\
\text { (b) Interpessoal e comunicação, referem-se à capacidade de um } \\
\text { contador profissional trabalhar e interagir eficazmente com os } \\
\text { outros (Intermediário); } \\
\text { (c) Pessoal, relaciona-se às atitudes e ao comportamento pessoal } \\
\text { de um contador profissional (Intermediário); } \\
\text { (d) Organizacional, relaciona-se com a capacidade de um } \\
\text { contador profissional trabalhar efetivamente com ou dentro de } \\
\text { uma organização para obter os melhores resultados ou resultados } \\
\text { das pessoas e recursos disponíveis (Intermediário). }\end{array}$ \\
\hline $\begin{array}{l}\text { Valores profissionais, } \\
\text { ética e atitudes (IES 4) }\end{array}$ & $\begin{array}{l}\text { (a) Ceticismo profissional e julgamento profissional (Intermediário); } \\
\text { (b) Princípios éticos; } \\
\text { (c) Compromisso com o interesse público (Intermediário) }\end{array}$ \\
\hline
\end{tabular}

Figura 2 - Competência profissional dos contadores e níveis de proficiência Fonte: Adaptado de IFAC (2019).

Observa-se, na Figura 2, que os IES estão relacionados com os níveis de proficiência fundamentais, intermediários e avançados, que descrevem a progressão típica que ocorre no desenvolvimento da competência profissional ao longo da carreira de um contador e são projetados para garantir que esses profissionais alcancem um nível apropriado de competência profissional, para atuarem em ambientes com baixos, moderados ou altos níveis de ambiguidade, complexidade e incerteza.

Chiu, Mahat, Rashid, Razak e Omar (2016) segregam as competências em hard skills e soft skills, e afirmam que os dois tipos de habilidades são indiscutivelmente imperativas para ter sucesso em uma profissão específica. Os autores definem hard skills como habilidades técnicas necessárias para realizar uma tarefa e que podem ser desenvolvidas por meio de treinamento e prática e, explicam que soft skills incorporam habilidades como comunicação eficaz, resolução de problemas, pensamento criativo e liderança. Para Kavanagh e Drennan (2008), muitas tarefas contábeis podem ser automatizadas e, diante 
disso, o valor do contador está cada vez mais refletido em habilidades de alto nível, como pensamento crítico, resolução de problemas e análise.

Nessa lógica, é notável que os níveis mais complexos da Taxonomia de Bloom (análise, síntese e avaliação) abrangem essas competências comportamentais, uma vez que instigam a resolução criativa de situações diversas e complexas, que, em muitos casos, são estranhas ao indivíduo, e, mesmo assim, este deverá ser capaz de identificar e antecipar-se ao fato, encontrando a solução adequada para a situação (Santana, Pereira \& Lopes, 2008). A avaliação, nesse caso, serve como medida da competência profissional. Logo, se o Exame de Suficiência não abrange as habilidades dos níveis mais complexos da Taxonomia de Bloom (análise, síntese e avaliação), que estão intimamente relacionadas com as competências requeridas pelo movimento de convergência (soft skills), ele não estará examinando adequadamente os egressos e, portanto estará desalinhado com o perfil requerido para os contadores conforme preconiza a IFAC.

\subsection{Estudos Anteriores}

A Taxonomia de Bloom tem sido utilizada em pesquisas na área contábil, como em análises de materiais didáticos de contabilidade (Davidson \& Baldwin, 2005), estudos que analisaram o nível cognitivo exigido em provas de concursos públicos para o cargo de contador (Santana et al., 2008; Lara \& Pereira, 2018) e em provas do Exame de Suficiência (Pinheiro et al., 2013; Silva, 2014; Martinez, 2017; Bernardes e Silva, 2019).

Davidson e Baldwin (2005) descreveram como a Taxonomia de Bloom foi usada para analisar o material de final de capítulo de 41 livros de ensino de contabilidade intermediária, publicados entre 1934 e 2004, por oito equipes de autores mais influentes, que produziram cinco ou mais edições cada. Os autores, que procuraram identificar a tendência na demanda cognitiva inerente aos finais desses capítulos, constituídos por questões de contabilidade intermediária, obtiveram, como principal resultado, que não houve uma mudança positiva significativa, ao longo de várias décadas, em materiais de contabilidade intermediária, considerando os níveis mais altos da Taxonomia de Bloom. Esses materiais enquadraram-se, em sua maioria, nos níveis 3 e 4. Os resultados encontrados pelos autores sugerem uma falta de alinhamento entre os materiais didáticos utilizados no ensino de contabilidade e as habilidades intelectuais necessárias para as carreiras contábeis. Na opinião dos autores citados, expor os alunos a itens de nível 5 e 6 é essencial para desenvolver as habilidades intelectuais necessárias, relacionadas à resolução criativa, identificação e antecipação de problemas.

No Brasil, Santana et al. (2008) detectaram, por meio dos seis níveis da Taxonomia de Bloom, qual a tendência das habilidades cognitivas requeridas, quando da demanda por profissionais contadores pela Administração Direta e Indireta da União. Para isso, os autores analisaram questões de algumas provas de concursos do período de 1999 a 2006, o que evidenciaria um perfil de desempenho intelectual delineado pelo setor público. O resultado da pesquisa demonstrou que não se está exigindo dos candidatos ao cargo de contador os mais altos indicadores de habilidades cognitivas, relativos aos níveis 4 (análise), 5 (síntese) e 6 (avaliação) da Taxonomia de Bloom. Os autores concluíram que há 
necessidade de mudanças efetivas nos rumos dessa profissão, para que se possa garantir o espaço almejado para todos aqueles que optaram em trabalhar na área das Ciências Contábeis.

Em uma proposta semelhante, Lara e Pereira (2018) verificaram, sob a perspectiva da Taxonomia de Bloom, o nível de habilidade cognitiva das questões de contabilidade societária exigidas nas provas de concursos públicos para bacharéis em Ciências Contábeis, entre os anos de 2010 e 2014. Os autores coletaram 58 provas no período compreendido na pesquisa, que totalizaram 750 questões de contabilidade societária. A partir dos resultados obtidos, os autores concluíram que os cargos de contador que possuem maior remuneração, nas três esferas de governo, tendem a não exigir questões de contabilidade societária com os níveis 4 (análise), 5 (síntese) e 6 (avaliação) de habilidade cognitiva, assemelhando-se às conclusões de Santana et al. (2008). Apesar de os editais de concurso público, analisados na pesquisa de Lara e Pereira (2018), na descrição das funções dos cargos exigirem os níveis de análise, síntese e avaliação (níveis 4, 5 e 6, respectivamente) não foi percebida tal exigência nas questões dos concursos. Assim, esses resultados indicam que existe um desalinhamento entre o perfil desejado do contador, especificamente após a convergência às IFRS, que são normas mais subjetivas e que exigem habilidades cognitivas mais complexas, e o que vem sendo cobrado nos concursos da área.

Por sua vez, Pinheiro et al. (2013) identificaram se os níveis de habilidades cognitivas demandados pelo Exame Nacional de Desempenho dos Estudantes (ENADE) e pelo Exame de Suficiência do CFC são aderentes ao perfil do contador estabelecido pelo Conselho Nacional de Educação (CNE), na perspectiva da Taxonomia de Bloom. Tais autores demonstraram que os níveis de habilidades cognitivas solicitados pelos exames não são aderentes ao perfil previsto pelo $\mathrm{CNE}$, destacando, também, que o percentual de questões no nível cognitivo mais alto foi inferior ao percentual de questões de menor exigência cognitiva. Assim, observa-se que há um descasamento entre o que é exigido pela legislação e o que vem sendo cobrado nos exames de regulação da educação contábil e certificação da profissão. Isso indica que, apesar da importância de se trabalhar os níveis cognitivos mais complexos, os avaliadores não estão preparando os seus exames para atender às demandas do mercado, advindas da convergência às IFRS.

Silva (2014) analisou como ocorre a equalização, ou seja, a uniformização das questões construídas para avaliar Habilidades Conceituais, Procedimentais e Atitudinais no Exame de Suficiência do CFC no período de 2012 e 2013, por meio da Taxonomia de Objetivos Educacionais e seus níveis de aprendizagem. Conforme o autor, os níveis conhecimento e compreensão são associados com as Habilidades Conceituais, os níveis aplicação e análise, com as Habilidades Procedimentais, e os níveis síntese e avaliação, com as Habilidades Atitudinais. Os resultados da pesquisa mostraram que o exame possui alta frequência de Habilidades Conceituais (57\%), moderada frequência de Habilidades Procedimentais (37\%) e baixa frequência de Habilidades Atitudinais (12\%). Silva (2014) conclui, assim, que o Exame de Suficiência está mais associado ao que se deve saber (Conceitual) e na dimensão do que se deve saber fazer (Procedimental), deixando de lado a vertente de como se deve ser (Atitudinal).

Ainda com relação ao Exame de Suficiência e às provas dos principais concursos públicos federais, Martinez (2017) analisou se esses instrumentos 
utilizam, em maior número, os itens principiológicos, ou seja, baseados em princípios. Motivada pela convergência às IFRS no Brasil, a autora procurou evidências de que o incentivo ou o direcionamento das avaliações às quais o egresso de Ciências Contábeis se submete em relação ao seu conhecimento poderia estar desalinhado aos novos ideais buscados pelas IFRS por meio dos princípios. Os resultados mostraram que há uma maior cobrança de regras nas provas analisadas. Dessa forma, nota-se um possível desalinhamento entre os ideais relacionados às IFRS e o direcionamento das avaliações de egressos da área contábil.

Por fim, Bernardes e Silva (2019) avaliaram o nível cognitivo das questões de Contabilidade do Exame de Suficiência, desde a primeira edição de 2014 até a segunda edição de 2016. Adicionalmente, realizaram uma comparação entre o nível cognitivo das questões e os resultados obtidos nos exames aplicados no período (aprovações e reprovações). Os resultados mostraram que o número de questões classificadas no menor nível cognitivo de todas as edições analisadas foi inferior ao número de questões classificadas no maior nível cognitivo, segundo a metodologia de classificação utilizada pelas autoras, exceto na primeira edição de 2015, o que pode ser um indício para os altos índices de reprovação no exame. Em outras palavras, existe a possibilidade dos índices de reprovação estarem crescendo devido ao aumento da exigência de maior nível cognitivo nas questões. Nesse sentido, as autoras argumentam que os cursos de graduação em Ciências Contábeis podem não estar privilegiando os objetivos educacionais, notadamente, aqueles que proporcionam atingir níveis cognitivos mais elevados.

Como pode ser observado, os estudos anteriores analisaram amostras e períodos, com distintos critérios de classificação das questões. Além desses aspectos, o presente estudo diferencia-se dos anteriormente realizados, notadamente pela proposta metodológica de validação, por especialistas, da classificação de questões dúbias quanto aos níveis cognitivos e pelo confronto destes com as competências e habilidades globalmente demandas do profissional contábil, de acordo com a IFAC.

\section{ASPECTOS METODOLÓGICOS}

Para alcançar o objetivo do trabalho, foi realizada a coleta de dados por meio eletrônico, no site do CFC (https://cfc.org.br). Foram coletadas as provas, os gabaritos e os relatórios estatísticos disponíveis referentes ao Exame de Suficiência de contador dos anos de 2011 a 2017, totalizando 14 edições do exame. A população desta pesquisa foi, então, constituída por 569 questões que trataram especificamente de Contabilidade, ou seja, foram excluídas as questões de Português, Matemática Financeira e Estatística e Noções de Direito.

Com relação aos procedimentos de análise dos dados, inicialmente utilizou-se a Taxonomia de Bloom para realizar a classificação das 569 questões, buscando identificar o nível cognitivo das mesmas (1. Conhecimento, 2. Compreensão, 3. Aplicação, 4. Análise, 5. Síntese, 6. Avaliação). Sendo assim, adotou-se como orientadores as descrições, verbos relacionados e os materiais ilustrativos (exemplos de questões) de cada nível cognitivo constantes na taxonomia original e conforme demonstrado na Figura 1, seção 2.1. 
Não obstante o grau de subjetividade presente nos níveis da taxonomia e na definição dos limites existentes entres estes, durante a classificação foram encontradas dificuldades para definir o nível cognitivo de 199 questões $134,97 \%$ do total). Assim, as questões que geraram dúvidas durante o processo de classificação foram denominadas "questões conflituosas" nesta pesquisa.

Em decorrência da subjetividade mencionada, pode surgir dúvida quanto ao fato das outras 370 questões classificadas $(65,03 \%$ do total) não terem sido entendidas como conflituosas e quais foram os critérios que levaram a uma classificação convicta. A esse respeito, argumenta-se que, no decorrer do processo de classificação, percebeu-se que as questões do Exame de Suficiência têm forma similar de edição para edição. Em outras palavras, a construção das questões enquadradas em um mesmo conteúdo e nível é feita de forma semelhante, como se fosse uma construção padronizada. Então, foram percebidas questões que eram similares na forma, no conteúdo e no objetivo educacional que pretendia alcançar, ou seja, esperavam comportamentos semelhantes dos respondentes, o que favoreceu a classificação. Destaca-se que essas são impressões alcançadas a partir da análise das 14 edições do exame, não estando isso formalizado em nenhum documento oficial do CFC e, portanto, podendo divergir das impressões e interpretações de outras pessoas.

Salienta-se que, para cada uma das 199 questões conflituosas, foram apontados dois níveis cognitivos, entre os quais não houve clareza, a partir dos critérios adotados para classificação, para indicar qual seria o mais apropriado. Na Tabela 1 é possível observar o número de questões conflituosas por níveis cognitivos das 14 edições do Exame de Suficiência analisadas.

\section{Tabela 1}

Total de questões conflituosas do Exame de Suficiência por nível cognitivo

\begin{tabular}{l|c}
\multicolumn{1}{c|}{ Níveis Cognitivos } & Total de Questões \\
\hline Aplicação ou Análise & 107 \\
\hline Compreensão ou Análise & 51 \\
\hline Conhecimento ou Compreensão & 36 \\
\hline Compreensão ou Aplicação & 5 \\
\hline Total & $\mathbf{1 9 9}$ \\
\hline
\end{tabular}

Fonte: Elaboração própria.

Pela Tabela 1, percebe-se que a maior dificuldade de diferenciação encontrada foi entre os níveis 3 e 4 da taxonomia, respectivamente, aplicação e análise (107 questões). A justificativa para essa dificuldade reside no fato de que é complexo afirmar se a questão demanda habilidades de compreensão e aplicação apenas, ou se a questão demanda, além da aplicação, uma análise mais aprofundada, ou seja, habilidades do nível 4 da taxonomia.

No intuito de minimizar a subjetividade da classificação, para as questões conflituosas foi realizado um processo de validação em quatro etapas, por meio da classificação das mesmas questões por quatro professoras de contabilidade, denominadas X, Y, Z e W, conhecedoras da Taxonomia de Bloom e atuantes em cursos de Ciências Contábeis, ou seja, conhecem o contexto em que os exames foram aplicados. 
Esse processo de validação está resumidamente demonstrado na Figura 3.

\begin{tabular}{|c|c|c|c|}
\hline Etapas & $1^{a}$ etapa & $2^{a}$ e $3^{a}$ etapa & $4^{a}$ etapa \\
\hline $\begin{array}{l}\text { Questões } \\
\text { conflituosas }\end{array}$ & 199 & 37 & 13 \\
\hline Professoras & $\mathrm{X}$ & $Y \in Z$ & $\mathrm{~W}$ \\
\hline Procedimentos & $\begin{array}{c}\text { A professora X } \\
\text { classificou as questões } \\
\text { e justificou a } \\
\text { classificação mediante } \\
\text { os critérios adotados na } \\
\text { pesquisa. } \\
\text { Posteriormente, foi } \\
\text { realizada uma reunião } \\
\text { entre a pesquisadora e } \\
\text { a professora X para } \\
\text { confrontação de } \\
\text { resultados e } \\
\text { averiguação de } \\
\text { divergências de } \\
\text { classificação. Caso } \\
\text { houvesse consenso na } \\
\text { reunião, a classificação } \\
\text { era alinhada, ao } \\
\text { contrário, era enviada } \\
\text { para a próxima etapa } \\
\text { da validação. }\end{array}$ & $\begin{array}{c}\text { As } 37 \text { questões } \\
\text { conflituosas que } \\
\text { restaram foram } \\
\text { enviadas para as } \\
\text { professoras Y e Z com } \\
\text { dois níveis cognitivos } \\
\text { indicados, } \\
\text { decorrentes da } \\
\text { primeira etapa. As } \\
\text { professoras Y e Z } \\
\text { classificaram as } \\
\text { questões e } \\
\text { justificaram a } \\
\text { classificação } \\
\text { utilizando os critérios } \\
\text { da pesquisa. } \\
\text { Questões que } \\
\text { continuassem } \\
\text { conflituosas eram } \\
\text { separadas e enviadas } \\
\text { para a próxima } \\
\text { etapa. }\end{array}$ & $\begin{array}{l}\text { As } 13 \text { questões } \\
\text { conflituosas que } \\
\text { restaram foram } \\
\text { enviadas para a } \\
\text { professora W com } \\
\text { dois níveis } \\
\text { cognitivos } \\
\text { indicados, } \\
\text { decorrentes da } \\
\text { etapa anterior. A } \\
\text { professora W } \\
\text { classificou as } \\
\text { questões e } \\
\text { justificou a } \\
\text { classificação } \\
\text { utilizando os } \\
\text { critérios da } \\
\text { pesquisa. }\end{array}$ \\
\hline
\end{tabular}

Figura 3 - Ełapas do processo de validação Fonte: Elaboração própria.

Posteriormente à validação da classificação, seguindo a proposta de Santana et al. (2008) e de Pinheiro et al. (2013), as questões foram agrupadas em duas categorias que englobam os seis níveis cognitivos da taxonomia: CCA (conhecimento, compreensão e aplicação) ou ASA (análise, síntese e avaliação), de acordo com sua complexidade. Assim, as questões que se enquadram nos níveis 1, 2 e 3 da taxonomia são consideradas menos complexas (CCA) e as questões que se enquadram nos níveis 4, 5 e 6 são consideradas mais complexas (ASA).

A classificação das questões do Exame de Suficiência nos seis níveis cognitivos da Taxonomia de Bloom e nas duas categorias cognitivas definidas (CCA e ASA) possibilitou a realização de uma análise descritiva e de uma análise crítica do exame. Para as informações adquiridas na apreciação dos relatórios estatísticos foram utilizadas técnicas de estatística descritiva para: comparar os níveis cognitivos com (i) o total de questões e (ii) o total de questões por conteúdo. Os resultados dessas análises são evidenciados na sequência. 


\section{APRESENTAÇÃO E ANÁLISE DOS RESULTADOS}

\subsection{Análise Descritiva do Nível cognitivo das Edições do Exame de Suficiência}

Observando a Tabela 2, nota-se que, nas questões de Contabilidade do Exame de Suficiência analisadas, os últimos níveis da Taxonomia de Bloom, na categoria ASA (53 questões), foram pouco requeridos, quando comparados com os níveis menos complexos, da categoria CCA (516 questões). Esses resultados vão ao encontro de estudos anteriores, como de Pinheiro et al. (2013), Silva (2014) e Martinez (2017).

Das questões enquadradas na categoria CCA, 194 foram classificadas como de aplicação, seguidas de 185 de compreensão e 137 de conhecimento, enquanto que, das questões enquadradas na categoria ASA, 51 foram classificadas no nível de análise e duas no nível de avaliação, não havendo, portanto, nenhuma questão enquadrada no nível de síntese.

\section{Tabela 2}

Número de questões por nível cognitivo do Exame de Suficiência por edição

\begin{tabular}{|c|c|c|c|c|c|c|c|}
\hline \multirow[t]{3}{*}{ Edição } & \multirow{3}{*}{$\begin{array}{c}\text { Questões } \\
\text { Classificadas }\end{array}$} & \multicolumn{6}{|c|}{$\mathrm{N}^{\circ}$ de questões por categoria e nível cognitivo } \\
\hline & & \multicolumn{3}{|c|}{ CCA } & \multicolumn{3}{|c|}{ ASA } \\
\hline & & Conhecimento & Compreensão & Aplicação & Análise & Síntese & Avaliação \\
\hline 2011 & 78 & 25 & 20 & 27 & 6 & 0 & 0 \\
\hline \multicolumn{2}{|c|}{ Total por categoria } & \multicolumn{3}{|c|}{72} & \multicolumn{3}{|c|}{6} \\
\hline \multicolumn{2}{|c|}{ \% por categoria } & \multicolumn{3}{|c|}{92,31} & \multicolumn{3}{|c|}{7,69} \\
\hline 2012 & 82 & 29 & 19 & 27 & 7 & 0 & 0 \\
\hline \multicolumn{2}{|c|}{ Total por categoria } & \multicolumn{3}{|c|}{75} & \multicolumn{3}{|c|}{7} \\
\hline \multicolumn{2}{|c|}{ \% por categoria } & \multicolumn{3}{|c|}{91,46} & \multicolumn{3}{|c|}{8,54} \\
\hline 2013 & 80 & 13 & 32 & 25 & 10 & 0 & 0 \\
\hline \multicolumn{2}{|c|}{ Total por categoria } & \multicolumn{3}{|c|}{70} & \multicolumn{3}{|c|}{10} \\
\hline \multicolumn{2}{|c|}{ \% por categoria } & \multicolumn{3}{|c|}{87,5} & \multicolumn{3}{|c|}{12,5} \\
\hline 2014 & 76 & 15 & 31 & 25 & 5 & 0 & 0 \\
\hline \multicolumn{2}{|c|}{ Total por categoria } & \multicolumn{3}{|c|}{71} & \multicolumn{3}{|c|}{5} \\
\hline \multicolumn{2}{|c|}{ \% por categoria } & \multicolumn{3}{|c|}{93,42} & \multicolumn{3}{|c|}{6,58} \\
\hline 2015 & 81 & 15 & 32 & 29 & 4 & 0 & 1 \\
\hline \multicolumn{2}{|c|}{ Total por categoria } & \multicolumn{3}{|c|}{76} & \multicolumn{3}{|c|}{5} \\
\hline \multicolumn{2}{|c|}{ \% por categoria } & & 93,83 & & & 6,17 & \\
\hline 2016 & 86 & 13 & 28 & 33 & 12 & 0 & 0 \\
\hline Total & or categoria & & 74 & & & 12 & \\
\hline$\% p$ & categoria & & 86,05 & & & 13,95 & \\
\hline 2017 & 86 & 27 & 23 & 28 & 7 & 0 & 1 \\
\hline Total & or categoria & & 78 & & & 8 & \\
\hline$\% p$ & categoria & & 90,70 & & & 9,30 & \\
\hline
\end{tabular}

Fonte: Elaboração própria.

Segundo Silva (2014), os níveis conhecimento e compreensão estão relacionados ao que se deve saber, os níveis aplicação e análise, ao que se deve 
saber fazer, e os níveis síntese e avaliação, ao que se deve ser. Nessa lógica, os resultados encontrados nesta pesquisa mostram que o Exame de Suficiência está mais associado ao que se deve saber e ao que se deve saber fazer. Em outras palavras, o exame está focado em cobrar bases teóricas e realizar determinados objetivos por meio de ações em situações concretas.

Na Resolução $n^{\circ} 1.486 / 2015$ do CFC, que regulamenta o Exame de Suficiência como requisito para obtenção de Registro Profissional em Conselho Regional de Contabilidade (CRC), é mencionado que são cobrados conhecimentos médios. Pela perspectiva de análise utilizada neste estudo, que é a Taxonomia de Bloom, pode-se depreender que tais conhecimentos médios estariam atendendo, predominantemente, os objetivos educacionais dos níveis cognitivos da categoria CCA. Caso essa circunstância se confirme, as instituições de ensino que privilegiem objetivos educacionais visando atingir os níveis da categoria CCA podem estar preparando futuros profissionais contábeis com conhecimentos medianos para obter certificação profissional, porém não para atender demandas globais da profissão, como preconizado pela IFAC.

Observando-se a Figura 4, percebe-se, de forma geral, que a quantidade de questões da categoria CCA e da categoria ASA não apresenta grandes oscilações de ano para ano, o que esclarece que o Exame de Suficiência concentra a maior parte de suas questões $190,69 \%$ do total de questões analisadas) nos níveis menos complexos da Taxonomia de Bloom. Uma possível justificativa para esse fato, apresentada por Santana et al. (2008), é a inexistência de questões discursivas no Exame de Suficiência, pois, de acordo com os autores, as questões classificadas nos dois últimos níveis da Taxonomia de Bloom †endem a ser discursivas e não objetivas.

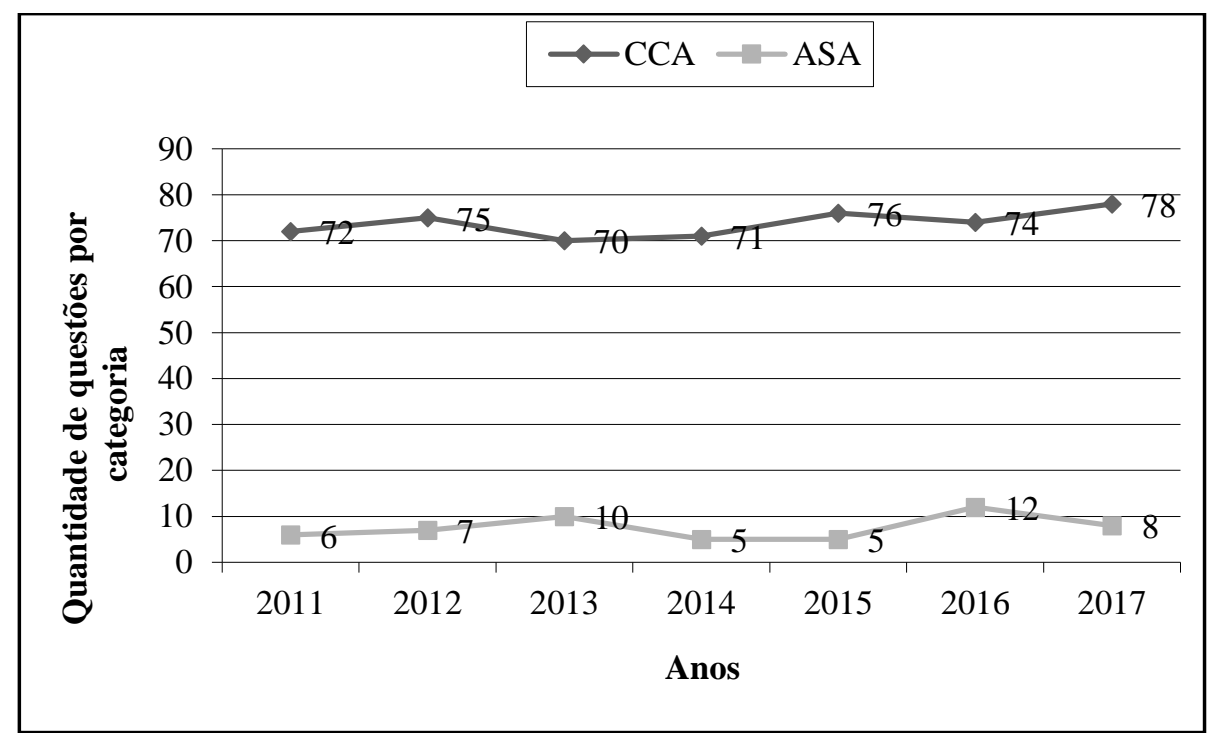

Figura 4 - Quantidade de questões CCA e ASA no Exame de Suficiência por ano Notas: CCA = Conhecimento, Compreensão e Aplicação; ASA = Análise, Síntese e Avaliação. Fonte: Elaboração própria.

Com o intuito de aprofundar a análise, apresenta-se, na Tabela 3 a quantidade de questões enquadradas em cada nível cognitivo da Taxonomia de Bloom, por conteúdo do Exame de Suficiência. 


\section{Tabela 1}

Questões por conteúdo e nível cognitivo do Exame de Suficiência

\begin{tabular}{|c|c|c|c|c|c|c|}
\hline \multirow[t]{2}{*}{ Conteúdo } & \multicolumn{6}{|c|}{ Níveis Cognitivos } \\
\hline & Conhecimento & Compreensão & Aplicação & Análise & Síntese & Avaliação \\
\hline $\begin{array}{l}\text { Auditoria } \\
\text { Contábil }\end{array}$ & 22 & 15 & 4 & 2 & 0 & 0 \\
\hline $\begin{array}{l}\text { Cont. Aplicada } \\
\text { ao Setor Público }\end{array}$ & 16 & 17 & 7 & 1 & 0 & 0 \\
\hline $\begin{array}{l}\text { Contabilidade } \\
\text { de Custos }\end{array}$ & 5 & 5 & 41 & 6 & 0 & 0 \\
\hline $\begin{array}{l}\text { Contabilidade } \\
\text { Geral }\end{array}$ & 25 & 74 & 109 & 22 & 0 & 0 \\
\hline $\begin{array}{l}\text { Cont. Gerencial } \\
\text { e Controladoria }\end{array}$ & 2 & 9 & 27 & 14 & 0 & 0 \\
\hline $\begin{array}{l}\text { Legislação e } \\
\text { Ética Profissional }\end{array}$ & 16 & 18 & 0 & 1 & 0 & 0 \\
\hline Perícia Contábil & 17 & 7 & 3 & 2 & 0 & 0 \\
\hline $\begin{array}{l}\text { Princípios e } \\
\text { Normas } \\
\text { Contábeis }\end{array}$ & 20 & 27 & 3 & 1 & 0 & 0 \\
\hline $\begin{array}{l}\text { Teoria da } \\
\text { Contabilidade }\end{array}$ & 14 & 13 & 0 & 2 & 0 & 2 \\
\hline Total & 137 & 185 & 194 & 51 & 0 & 2 \\
\hline
\end{tabular}

Fonte: Elaboração própria.

Observa-se na Tabela 3, que o conteúdo de Contabilidade Geral, que é o mais cobrado no Exame de Suficiência, apresenta o maior número de questões enquadradas nos níveis aplicação (109) e compreensão (74. Percebe-se, também, que a maioria das questões de Contabilidade de Custos estão acumuladas no nível aplicação, o que também acontece com Contabilidade Gerencial e Controladoria.

Silva (2014) relaciona o nível aplicação ao que se deve saber fazer, ou seja, habilidades procedimentais. O fato desses três conteúdos apresentarem mais questões nesse nível pode ser justificado pelo grande número de situações que envolvem o uso dessas disciplinas no cotidiano da profissão contábil. Segundo Lunkes, Rosa, Silva e Bernardes (2015), nota-se uma ênfase maior na cobrança de questões relacionadas a cálculos e métodos, do que a sua utilização na tomada de decisão. Visto que o contador, no dia a dia, possivelmente terá que colocar em prática, tanto a parte técnica quanto a de decisão e julgamento, é essencial que ele esteja familiarizado com essas habilidades e saiba analisar e interpretar as informações para tomada de decisão e não só lidar com a preparação de demonstrações financeiras.

Assim, diante do exposto até aqui, percebe-se que, apesar da literatura apontar a necessidade de desenvolver competências, como análise e interpretação de informação para tomada de decisão, julgamento, pensamento crítico, comunicação e outras, por serem tidas como diferenciais na profissão contábil, principalmente após a convergência às IFRS, esses aspectos têm sido negligenciados pelo processo de certificação do Brasil. Segundo Lunkes et al. (2015) não é possível dizer que o contador terá as noções mínimas para a prática da contabilidade, a partir da aprovação no Exame de Suficiência e do posterior registro no $C R C$, visto que a prova não possui questões discursivas, nem exige dos candidatos aplicar seus conhecimentos em situações complexas e práticas, 
através de casos, por exemplo. Para os autores citados, o CFC pode ser um instrumento para impulsionar uma melhor qualidade do ensino de Contabilidade, mas, para isso, deve evitar a padronização das questões e utilizar a abordagem interpretativa, pois, assim, o bacharel terá que utilizar raciocínios analíticos, conhecer aspectos comportamentais e habilidades de gestão.

Com o objetivo de complementar o estudo, verificou-se o percentual de aprovados e reprovados nas edições do Exame de Suficiência de 2011 a 2017, divulgado pelo CFC, conforme apresentado na Tabela 4, e constatou-se uma elevada taxa de reprovação. Avulta-se as edições 2012.2, 2015.2, 2016.2, 2017.1 e 2017.2, nas quais os percentuais de reprovações foram, respectivamente, $73,95 \%, 85,32 \%, 78,11 \%, 74,74 \%$ e $72,98 \%$. Em outras palavras, essas foram as edições do exame com maior número de reprovações, dentre as edições analisadas.

\section{Tabela 2}

Aprovados e reprovados no Exame de Suficiência

\begin{tabular}{c|c|c|c|c}
\hline Exame & Total Aprovados & (\%) Aprovados & $\begin{array}{c}\text { Total } \\
\text { Reprovados }\end{array}$ & (\%) Reprovados \\
\hline $1^{\circ} / 2011$ & 4.130 & 30,86 & 9.253 & 69,14 \\
\hline $2^{\circ} / 2011$ & 10.886 & 58,29 & 7.789 & 41,71 \\
\hline $1^{\circ} / 2012$ & 11.705 & 47,25 & 13.069 & 52,75 \\
\hline $2^{\circ} / 2012$ & 7.613 & 26,05 & 21.613 & 73,95 \\
\hline $1^{\circ} / 2013$ & 12.000 & 35,60 & 21.708 & 64,40 \\
\hline $2^{\circ} / 2013$ & 15.891 & 43,14 & 20.942 & 56,86 \\
\hline $1^{\circ} / 2014$ & 18.824 & 49,39 & 19.292 & 50,61 \\
\hline $2^{\circ} / 2014$ & 13.591 & 41,73 & 18.977 & 58,27 \\
\hline $1^{\circ} / 2015$ & 20.715 & 54,48 & 17.308 & 45,52 \\
\hline $2^{\circ} / 2015$ & 5.580 & 14,68 & 32.442 & 85,32 \\
\hline $2^{\circ} / 2016$ & 17.576 & 41,86 & 24.411 & 58,14 \\
\hline $1^{\circ} / 2017$ & 8.948 & 21,89 & 31.931 & 78,11 \\
\hline $2^{\circ} / 2017$ & 11.860 & 25,26 & 35.089 & 74,74 \\
\hline Total Geral & 12.041 & 35,87 & 32.516 & 72,98 \\
\hline
\end{tabular}

Fonte: Elaboração própria com base nos relatórios estatísticos do CFC.

Na Tabela 4 verifica-se uma tendência de queda nos níveis de aprovação a partir da segunda edição de 2015, com exceção da edição 2016.1, que apresentou uma melhora significativa, se comparada à edição anterior e às posteriores. Destaca-se que o pico do índice de reprovações $(85,32 \%)$ encontrase em 2015.2. Em complemento, a segunda edição do exame de 2011 , foi a que apresentou nível de reprovação mais baixo $(41,71 \%)$.

Diante do exposto, nota-se altos índices de reprovação, principalmente nos últimos anos, mesmo que as questões do Exame de Suficiência apresentem um baixo nível cognitivo. Esse fato permite deduzir que o conhecimento dos alunos, de um modo geral, está abaixo do requerido pelo exame. Martinez (2017) afirma que nos exames de suficiência do CFC, a avaliação é feita com base no ensino que o aluno deveria ter recebido para se tornar um profissional apto ao mercado de trabalho, de acordo com os conhecimentos mínimos requeridos do curso. Bernardes e Silva (2019) alertam que os cursos de graduação em Ciências Contábeis podem não estar privilegiando os objetivos educacionais, notadamente, aqueles que proporcionam atingir níveis cognitivos mais elevados. 
Consequentemente, volta-se a atenção para as instituições de ensino superior, responsáveis por preparar os futuros profissionais da contabilidade, pois, se o desempenho dos alunos está abaixo do esperado, deduz-se que as instituições não estão conseguindo cumprir o desafio de fornecer aos seus alunos um ensino de qualidade, que acompanhe as mudanças da economia globalizada.

Nessa lógica, Bugarim, Rodrigues, Pinho e Machado (2014) e Souza, Cruz e Lyrio (2017) apontam que a explicação para esse alto índice de reprovação no exame pode estar relacionada com a qualidade dos cursos de graduação em Ciências Contábeis e ao desempenho dos discentes. Assim, acredita-se que é necessário melhorar a formação dos profissionais de Contabilidade, visto que há fragilidade no ensino. Diante de tudo o que foi apresentado, considera-se que os três últimos níveis cognitivos da Taxonomia de Bloom não são adequadamente exigidos nas provas do CFC, principalmente quando relacionados às competências esperadas do contador pela IFAC.

\subsection{Análise do Nível Cognitivo do Exame de Suficiência versus Competências}

Segundo dados do CFC (2018), no Brasil o curso de Ciências Contábeis é o quinto maior em termos de quantidade de vagas oferecidas. Esse número traz preocupações em relação à qualidade do ensino. Questiona-se se esses profissionais estão recebendo uma educação de qualidade das instituições de ensino, devido, principalmente, às mudanças mundiais que afetam o ensino da Contabilidade.

O papel das instituições de ensino superior é fundamental para o desenvolvimento dos profissionais contábeis. Essas instituições devem proporcionar, além de formação técnica, o desenvolvimento de habilidades interpessoais, de comunicação e de gestão (Bugarim, Alencar, Garcia \& Caddah, 2018). Soma-se à preocupação com a qualidade da educação oferecida pelas instituições, a necessidade de que os instrumentos de avaliação, no caso desta pesquisa, o Exame de Suficiência, estejam alinhados com as exigências atuais do mercado, principalmente em relação às competências advindas do processo de convergência às normas internacionais de contabilidade no Brasil.

Conforme o CFC (2018), o órgão tem acompanhado a evolução do processo de ensino nos últimos anos, principalmente por meio de iniciativas voltadas para a qualificação profissional. Mas, diante dos resultados encontrados nesta pesquisa a respeito do nível cognitivo exigido nas provas, questiona-se se estão sendo exigidas dos bacharéis as competências necessárias no mercado atual, que demanda mais que habilidades técnicas. A convergência às IFRS trouxe a necessidade de profissionais mais críticos, capazes de fazer julgamentos e tomar decisões, diante das normas baseadas em princípios e não em regras.

Dessa forma, como houve uma evolução nas competências esperadas dos contadores, o exame de certificação nacional precisa evoluir, juntamente com o processo de ensino e a convergência contábil, visto que o próprio órgão considera imprescindível acompanhar a evolução do ensino. Levando em consideração que o desenvolvimento dessas competências é avaliado, em sua maioria, por questões enquadradas nos dois níveis mais complexos da Taxonomia 
de Bloom (síntese e avaliação), e que neste trabalho foram enquadradas apenas 2 questões no nível 6 (avaliação), das 569 analisadas, infere-se que o Exame de Suficiência, não aborda adequadamente os níveis cognitivos mais altos, e, consequentemente, não tem evoluído juntamente com a convergência.

Comparando-se o Exame de Suficiência no Brasil com o processo de certificação internacional, por exemplo, o Certified Public Accountant (CPA) nos Estados Unidos, observam-se diferenças significativas na estrutura da prova. $O$ exame nacional não apresenta grande variação no padrão de questões, ou seja, as edições são compostas por questões muito parecidas e todas de múltipla escolha, o que, conforme relatado, pode dificultar a cobrança dos níveis mais altos da Taxonomia de Bloom. Já a certificação internacional é formada por questões variadas, como múltipla escolha, casos, atividades baseadas em tarefas, ou seja, a estrutura da prova é diferente e proporciona a abordagem dos níveis cognitivos mais altos da taxonomia. O CFC também precisa se posicionar melhor em relação às habilidades que caracterizam os conhecimentos medianos exigidos. O American Institute of Certified Public Accountants (AICPA), por exemplo, publica nos Blueprints do Exame único para CPA, os níveis de habilidades a serem avaliados em cada seção do exame, baseado nos níveis da Taxonomia de Bloom, o que serve como orientação para as instituições de ensino e, até mesmo, para os bacharéis entenderem quais habilidades estão sendo requeridas.

Cardoso, Mendonça e Oyadomari (2010) chamam a atenção para o fato de que não existe uma ou outra competência a ser priorizada, e sim, um conjunto de competências que formam um profissional. Nesse sentido, o CFC precisa ponderar sobre a importância de o exame apresentar um equilíbrio entre os níveis cognitivos para que, assim, sejam exigidas dos bacharéis, competências relacionadas com os níveis mais complexos da taxonomia, que afetam diretamente o ensino e a profissão contábil no Brasil. Segundo, Santana et al. (2008), o contador precisa possuir habilidades cognitivas na categoria mais complexa (ASA), levando em consideração o perfil esperado desse profissional. Para os autores, o contador não é mais considerado apenas por sua capacidade técnica, mas também pela gerencial.

Nesta pesquisa, verificou-se que das 569 questões analisadas nem 10\% (53 questões) foram classificadas na categoria cognitiva mais complexa (ASA). Visto que o perfil dos contadores previsto pela IFAC solicita habilidades dos níveis mais complexos da Taxonomia de Bloom, conclui-se que o nível exigido pelo Exame de Suficiência não adere à esse perfil, ou seja, há uma carência de cobrança de níveis mais elevados. No trabalho de Galvão (2016), encontram-se indicações de profissionais da Contabilidade à esse respeito, como, por exemplo, que a prova apresente questões discursivas e casos que instiguem o pensamento crítico dos contadores.

O conjunto de habilidades profissionais (intelectuais, interpessoais e de comunicação, pessoais e organizacionais) que norteiam a formação do contador, apresentado no IES 3 da IFAC, está muito mais associado ao contexto atual do que a Resolução n. 10/2004 do Conselho Nacional de Educação (CNE). Para Lemes e Miranda (2014), as habilidades preconizadas pela IFAC, para 0 contexto internacional, estão alinhadas às necessidades dos profissionais da contabilidade e a adoção de tais habilidades deve ser considerada na construção dos projetos pedagógicos dos cursos de Ciências Contábeis no Brasil. 
Sendo o Exame de Suficiência uma certificação para atuação profissional do contador, entende-se que as competências e habilidades para atuação no mercado global devem ser consideradas. Em outras palavras, o Exame de Suficiência não é apenas uma avaliação da qualidade do ensino de Contabilidade, mas sim, uma permissão para atuar profissionalmente como contador. Nessa linha, acredita-se ser compreensível que o mesmo deva refletir as competências demandas para atuação no mercado.

A partir dos resultados obtidos e das discussões realizadas, a confrontação do nível cognitivo do Exame de Suficiência, baseado nos objetivos educacionais da Taxonomia de Bloom, com as habilidades e competências requeridas do contador, pode ser resumida conforme demonstrado na Figura 5.

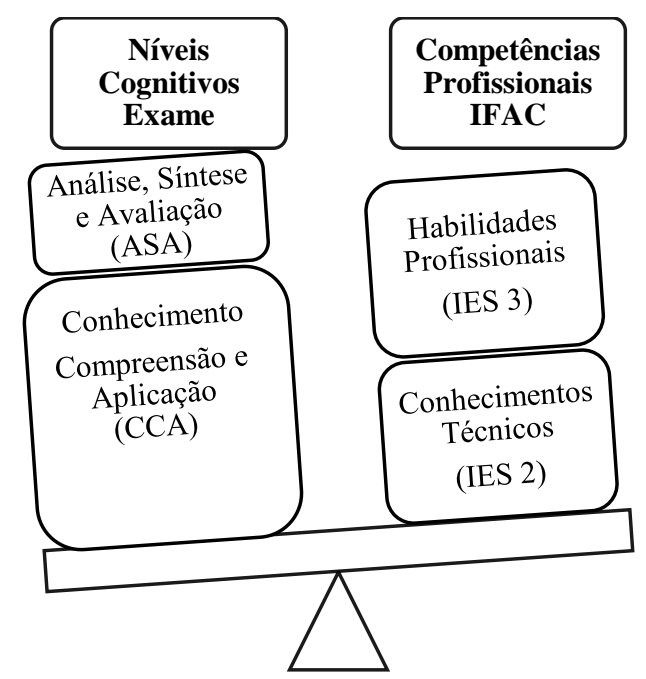

Figura 5 - Confrontação entre níveis cognitivos e competências profissionais Fonte: Elaboração própria.

Entende-se que há um desequilíbrio entre o que é cobrado na prova de certificação profissional e as competências demandadas para atuação. De outro modo, o presente estudo está demonstrando que o desenvolvimento das competências profissionais previstas pela IFAC é favorecido quando são alcançados os objetivos educacionais dos mais altos níveis cognitivos da Taxonomia de Bloom e que o órgão regulador e fiscalizador da profissão contábil no Brasil poderia utilizar, assim como o AICPA, a perspectiva da taxonomia para elaboração do exame, buscando o equilíbrio. Adicionalmente, entende-se que o processo educacional é muito mais amplo e complexo, cabendo às instituições de ensino essa mesma visão, ou seja, formar futuros profissionais capazes de atingir os níveis cognitivos mais altos da taxonomia, com vistas a desenvolver as competências profissionais necessárias para atuação no mercado global.

\section{CONSIDERAÇÕES FINAIS}

Essa pesquisa teve como objetivo confrontar o nível cognitivo do Exame de Suficiência com as habilidades e competências requeridas do contador a partir dos objetivos educacionais da Taxonomia de Bloom. 
O resultado da classificação das questões mostrou que o exame possui 90,69\% (516 questões) de predominância da categoria menos complexa - CCA (conhecimento, compreensão e aplicação). Dessa forma, esse resultado alinhase ao encontrado na literatura (Pinheiro et al., 2013; Silva, 2014; Martinez, 2017), visto que evidenciou que o Exame de Suficiência apresenta baixo nível cognitivo, ou seja, não explora adequadamente as habilidades relacionadas aos níveis mais altos da Taxonomia de Bloom - ASA (análise, síntese e avaliação).

Com isso, conclui-se que o baixo índice $(9,31 \%)$ apresentado de questões enquadradas na categoria mais complexa ASA, pode se justificar pela forma somativa da avaliação. Esse tipo de avaliação é realizado por meio de instrumentos, em sua maioria, constituídos por questões de múltipla escolha, ou seja, são testes objetivos que mostram-se práticos e confiáveis e, por isso, ganham forma por meio de exames relevantes como os de certificação e os vestibulares.

É possível concluir, também, por meio da análise do nível cognitivo do Exame de Suficiência, que, apesar de o nível cognitivo apresentado nos últimos anos ser baixo, os índices de reprovação são altos. Isso, possivelmente, indica um baixo grau de conhecimento dos egressos dos cursos de Ciências Contábeis no Brasil, e, consequentemente, uma deficiência na qualidade do ensino.

No tocante à confrontação do nível cognitivo do exame com as habilidades e competências requeridas do contador, concluiu-se que o CFC, apesar de considerar imprescindível acompanhar a evolução do ensino e as mudanças contábeis globais, não têm abordado de forma adequada, em seu exame, as competências demandadas do contador no mercado atual. Com a convergência às IFRS, houve uma evolução nas competências esperadas desses profissionais, surgindo a necessidade de desenvolver habilidades como pensamento crítico, capacidade de realizar julgamentos e tomar decisões, capacidade de comunicação, de resolução de problemas, entre outras denominadas soft skills, que, em um contexto de contabilidade baseada em regras, não eram consideradas como essenciais.

Considerando que o desenvolvimento dessas novas competências está relacionado com questões enquadradas nos níveis mais complexos da Taxonomia de Bloom (análise, síntese e avaliação), e que verificou-se carência de questões classificadas nessa categoria cognitiva, infere-se que o Exame de Suficiência não aborda adequadamente os níveis cognitivos mais altos e, consequentemente, não têm evoluído juntamente com $o$ ensino e a convergência contábil global. Tendo em mente o fato de que não existe uma ou outra competência a ser priorizada, e sim, um conjunto de competências que formam um profissional, o CFC precisa ponderar sobre a importância de o exame apresentar um equilíbrio entre as categorias cognitivas para que, assim, sejam exigidas dos bacharéis, competências relacionadas com os níveis mais complexos da taxonomia, que afetam diretamente o ensino e a profissão contábil no Brasil.

Nesse sentido, seria interessante, apesar de mais custoso, que o CFC diversificasse a forma de avaliação, utilizando, além da prova de múltipla escolha, questões discursivas, que possibilitam, com maior facilidade, explorar os níveis cognitivos mais altos e, até mesmo, a apresentação de casos e a possibilidade de estágios supervisionados, para testar os conhecimentos dos bacharéis, assim como a certificação internacional dos Estados Unidos (CPA). Esse 
processo avaliativo poderia promover a aproximação entre a academia e o mercado. Outra crítica levantada é a da necessidade de atualização da Resolução do Conselho Nacional de Educação CNE/CES n. 10/2004, uma vez que o conjunto de habilidades profissionais apresentado na Resolução, foi elaborado em um contexto profissional muito diferente do que ocorre atualmente (Lemes \& Miranda, 2014). Assim, as normas precisam acompanhar as mudanças ocorridas na prática.

Esta pesquisa oferece contribuições tanto para as instituições de ensino superior, quanto para o CFC, professores, alunos e mercado. No que diz respeito à contribuição para as instituições de ensino, este estudo é capaz de motivar essas instituições a acompanhar as mudanças no perfil profissional desejado e priorizar o desenvolvimento da capacidade cognitiva dos futuros contadores, bem como estabelecer objetivos educacionais claros e específicos, de modo que seja possível acompanhar sua evolução.

No tocante à contribuição ao CFC, este estudo visa agregar informações que sejam úteis ao órgão, para que possa alinhar o que é cobrado no Exame de Suficiência com o currículo do curso de Ciências Contábeis e com o perfil desejado pelo mercado para os contadores (habilidades e competências). Em relação à contribuição para professores, alunos e mercado, a disponibilização deste estudo, permitirá que esses compreendam como é construído o Exame de Suficiência e se o CFC considera, na sua elaboração, as competências que os bacharéis e discentes de Ciências Contábeis precisam desenvolver ou aprimorar para atuar profissionalmente, segundo as práticas globais de Contabilidade.

Não existe uma regra ou delimitação rígida entre as características que levam à determinada classificação para as questões, sendo preponderante a percepção do pesquisador ao definir o nível cognitivo. Com isso, embora nesta pesquisa tenha sido utilizada metodologia com base na Taxonomia de Bloom e uma validação da classificação, é importante ressaltar que não se desconsiderou o grau de subjetividade no processo, o que pode ser tratado como uma limitação do estudo. Para estudos futuros, sugere-se continuar buscando aprimoramentos metodológicos para trabalhar com essa temática. Outra possibilidade de continuidade para os estudos correlatos, seria avaliar os currículos e o perfil dos egressos almejados pelas instituições, confrontando-os com os objetivos educacionais e as competências profissionais.

\section{REFERÊNCIAS}

Bernardes, I. G., \& Silva, D. M. (2019). Nível cognitivo requerido nos exames de suficiência do CFC na perspectiva da Taxonomia de Bloom. Revista Mineira de Contabilidade, 20(edição especial), pp. 47-58. DOI: https://doi.org/10.21714/2446-9114RMC2019v20net04

Bloom, B. S., Engelhart, M. D., Furst, E. J., Hill, W. H., \& Krathwohl, D. R. (1983). Taxonomia de objetivos educacionais: domínio cognitivo. Porto Alegre/Rio de Janeiro: Editora Globo.

Bugarim, M. C. C., Rodrigues, L. L., Pinho, J. C. C., \& Machado, D. Q. (2014). O desempenho dos profissionais de Contabilidade no Exame de Suficiência do 
CFC: uma análise de conglomerados regionais. Revista de Contabilidade e Organizações, 22, pp. 60-71. DOI: https://doi.org/10.11606/rco.v8i22.61176

Bugarim, M. C. C., Alencar, R. C., Garcia, E. A. R., \& Caddah Neto, E. D. (2018). Exame de Suficiência: um requisito para a qualificação profissional. Brasilia: Conselho Federal de Contabilidade.

Cardoso, R., Mendonça Neto, O. R., \& Oyadomari, J. (2010). Os Estudos internacionais de competências e os conhecimentos, habilidades e atitudes do contador gerencial brasileiro: análises e reflexões. Brazilian Business Review, 7(3), pp. 91-113. DOl: http://dx.doi.org/10.15728/bbr.2010.7.3.5

Chiu, L. K., Mahat, N. I., Rashid, B., Razak, N. A., \& Omar H. (2016). Assessing Students' Knowledge and Soft Skills Competency in the Industrial Training Programme: The Employers' Perspective. Review of European Studies, 8(1), pp. 123-133. DOI: http://dx.doi.org/10.5539/res.v8n1p123

Davidson, R. A., Baldwin, B. A. (2005). Cognitive skills objectives in intermediate accounting textbooks: evidence from end-of-chapter material. Journal of Accounting Education, 23(2), pp. 79-95. DOI: https://doi.org/10.1016/j.jaccedu.2005.05.001

Galvão, N. (2016). Percepção dos contadores sobre o Exame de Suficiência do CFC. Revista Catarinense da Ciência Contábil, 15(45), pp.49-62. DOI: http://dx.doi.org/10.16930/2237-7662/rccc.v15n45p49-62

Gomes, G. S. (2018). Modelo de Aprendizagem Integral (MAI): um novo modelo para o ensino de contabilidade. Tese de Doutorado em Controladoria e Contabilidade, Faculdade de Economia, Administração e Contabilidade da Universidade de São Paulo, Ribeirão Preto, SP, Brasil.

Haydt, R.C. (1991). Avaliação do processo ensino-aprendizagem. (2. ed.) São Paulo: Ática.

International Federation of Accountants - IFAC (2019). Handbook of International Education Pronouncements. Recuperado em 16 janeiro, 2020 de https://www.ifac.org/publications-resources/2017-handbook-internationaleducation-pronouncements

Kavanagh, M. H., \& Drennan, L. (2008). What skills and attributes does an accounting graduate need? Evidence from student perceptions and employer expectations. Accounting and Finance, 48(2), pp. 279-300. DOl: https://doi.org/10.1111/j.1467-629X.2007.00245.x

Lara, L. D., Pereira, E. M. (2018). Concurso público para bacharéis em Ciências Contábeis no Brasil: uma análise das provas à luz da Taxonomia de Bloom. Revista de Contabilidade da UFBA, 12(1), pp. 91-114. DOI: http://dx.doi.org/10.9771/rc-ufba.v12i1.20593 
Lemes, D. F.; Miranda, G. J. (2014). Habilidades profissionais do contador preconizadas pela IFAC: um estudo com profissionais da região do Triângulo Mineiro. Advances in Scientific and Applied Accounting, 7(2), pp. 293-316. DOI: http://dx.doi.org/10.14392/asaa.2014070206

Lunkes, R. J., Rosa, F. S., Silva, D. F., \& Bernardes, R. (2015). Análise do Exame de Suficiência do CFC: um estudo sobre as questões de Contabilidade Gerencial. Revista Brasileira de Contabilidade, 210, pp. 26-39.

Martinez, A. L. (2017). Aprovados, mas...capacitados? Um estudo sobre princípios versus regras nos exames de suficiência e em provas de concursos públicos. Dissertação de Mestrado em Controladoria e Contabilidade, Faculdade de Economia, Administração e Contabilidade da Universidade de São Paulo, São Paulo, SP, Brasil.

Pelissoni, A. M. S. (2009). Objetivos educacionais e avaliação da aprendizagem. Anuário da Produção Acadêmica Docente, 3(5), pp. 129-139.

Pinheiro, F. M. G., Dias Filho, J. M., Lima Filho, R. N., \& Lopes, L. M. S. (2013). O perfil do contador e os níveis de habilidades cognitivas nos exames ENADE e Suficiência do CFC: uma análise sob a perspectiva da Taxonomia de Bloom. Contextus Revista Contemporânea de Economia e Gestão, 11 (1), pp. 50-65. DOI: https://doi.org/10.19094/contextus.v1 1i1.32157

Santana Júnior, J. J. B., Pereira, D. M. V. G., \& Lopes, J. E. G. (2008). Análise das habilidades cognitivas requeridas dos candidatos ao cargo de contador na Administração Pública Federal, utilizando-se indicadores fundamentados na visão da Taxonomia de Bloom. Revista Contabilidade e Finanças, 19(46), pp. 108-121. DOI: https://doi.org/10.1590/S1519-70772008000100009

Shaftel, J., \& Shaftel, T. L. Educational Assessment and the AACSB (2007). Issues in Accounting Education, 22(2), pp. 215-232. DOI: https://doi.org/10.2308/iace.2007.22.2.215

Silva, M. Z., Theiss, V., \& Rausch, R. R. (2013). Avaliação da aprendizagem na educação superior: relato de uma experiência. RACE Revista de Administração, Contabilidade e Economia, Ed. especial Anpad, pp. 363-396.

Silva, O. L. (2014). Avaliação das habilidades conceituais, procedimentais e atitudinais: estudo no Exame de Suficiência em Contabilidade 2012-2013. Dissertação de Mestrado em Contabilidade Financeira e Finanças, Universidade Federal do Paraná, Curitiba, PR, Brasil.

Souza, P. V. S., Cruz, U. N., \& Lyrio, E. F. (2017). A relação do Exame de Suficiência contábil com o desempenho discente e a qualidade dos cursos superiores em Ciências Contábeis do Brasil. Revista Ambiente Contábil, 9(2), pp. 179-199. 


\section{CONTRIBUIÇÕES DOS AUTORES}

\begin{tabular}{|l|c|c|}
\hline \multicolumn{1}{|c|}{ Contribuição } & $\begin{array}{c}\text { Daniella Andrade } \\
\text { Arantes }\end{array}$ & $\begin{array}{c}\text { Denise Mendes } \\
\text { da Silva }\end{array}$ \\
\hline $\begin{array}{l}\text { 1. Idealização e concepção do assunto e tema da } \\
\text { pesquisa }\end{array}$ & $\checkmark$ & $\checkmark$ \\
\hline 2. Definição do problema de pesquisa & $\checkmark$ & $\checkmark$ \\
\hline 3. Desenvolvimento da Plataforma Teórica & $\checkmark$ & \\
\hline $\begin{array}{l}\text { 4. Delineamento da abordagem metodológica da } \\
\text { pesquisa }\end{array}$ & $\checkmark$ & \\
\hline 5. Coleta de dados & $\checkmark$ & \\
\hline 6. Análises e interpretações dos dados coletados & $\checkmark$ & \\
\hline 7. Conclusões da pesquisa & $\checkmark$ & $\checkmark$ \\
\hline 8. Revisão crítica do manuscrito & & $\checkmark$ \\
\hline $\begin{array}{l}\text { 9. Redação final do manuscrito, conforme as normas } \\
\text { estabelecidas pela Revista. }\end{array}$ & & $\checkmark$ \\
\hline 10. Orientação & & \\
\hline
\end{tabular}

